\title{
Title
}

Young adult smokers' perceptions of plain packaging: A pilot naturalistic study

\section{Author names}

Crawford Moodie, Anne Marie Mackintosh, Gerard Hastings, Allison Ford

\section{Institutional affiliations}

Institute for Social Marketing, University of Stirling, Stirling, Scotland

\section{Correspondence}

Crawford Moodie, Institute for Social Marketing, University of Stirling, Stirling FK9

4LA, UK, tel: +44 (01786) 466645, fax: +44 (10786) 463535, e-mail:

c.s.moodie@stir.ac.uk

\section{Funding}

Cancer Research UK

\section{Licence Statement}

The Corresponding Author, Crawford Moodie, has the right to grant on behalf of all authors and does grant on behalf of all authors, an exclusive licence (or non-exclusive for government employees) on a worldwide basis to the BMJ Publishing Group Ltd and its Licensees to permit this article (if accepted) to be published in Journal Tobacco Control editions and any other BMJPGL products to exploit all subsidiary rights. 


\title{
Young adult smokers' perceptions of plain packaging: A pilot naturalistic study
}

\begin{abstract}
Aims: To explore the impact, if any, that using plain (non-branded) cigarette packs in real-life settings has upon young adult smokers.
\end{abstract}

Methods: Naturalistic type research was employed, where smokers used brown 'plain' packs for two weeks and their regular packs for two weeks, in real-life settings. Participants were recruited in Glasgow, Scotland. Of the 140 smokers, aged 18 to 35 years, that participated in the naturalistic study, 48 correctly completed and returned all questionnaires. Over the four-week study period participants completed a questionnaire twice a week assessing pack perceptions and feelings, feelings about smoking, salience of health warnings and smoking related behaviours. A sub-sample of 18 participated in a post-study interview, which employed a semi-structured topic guide to assess perceptions and experiences of using plain packs.

Results: Trends in the data show that in comparison to branded packaging, plain packaging increased negative perceptions and feelings about the pack and about smoking. Plain packaging also increased avoidant behaviour (hiding the pack, covering the pack), certain smoking cessation behaviours, such as smoking less around others and forgoing cigarettes, and thinking about quitting. Almost half $(\mathrm{N}=8)$ of those in the post-study interview, predominantly females $(\mathrm{N}=6)$, reported that the use of plain packs had either increased avoidant behaviour or reduced consumption. 
Conclusions: Our pilot naturalistic study suggests that plain packaging could potentially help reduce tobacco consumption among some young adult smokers, and females in particular. Employing an innovative research methodology our findings are consistent with, and indeed support, past plain packaging research.

Keywords: Tobacco, plain packaging, young adults 


\section{INTRODUCTION}

It is a quarter of a century since the use of plain brown wrappers for tobacco products was first suggested by Canadian doctors, who pointed out the anomaly of permitting such a dangerous product to be 'dressed up'. ${ }^{1}$ Since then the debate on plain packaging has continued. This has centred around four main issues: 1) tobacco industry costs, 2) counterfeiting and pricing, 3) legality and 4) proportionality.

Costs: Tobacco companies argue that plain packaging would cause them significant additional costs for pack redesign and printing. However, this would be a one-off expense - once plain packs were introduced they would, by definition, remain much the same thereafter. This contrasts with the present situation, where the pack shape, livery and method of opening is continuously researched and redesigned - the costs of which are both considerable ${ }^{\underline{2}}$ and on-going. In this sense, then, plain packaging is a cheaper option for tobacco companies.

Counterfeiting and pricing: Tobacco companies argue that plain packaging would stimulate growth in counterfeit tobacco as it would be easier, and cheaper, to produce. This would combine with a tendency for them to compete more assiduously on price one of their few remaining marketing tools - to drive down prices. This, in turn, would encourage consumption and outweigh the public health benefits of plain packaging. ${ }^{3}$ However, both assumptions are questionable. First there is no evidence to suggest plain packaging would increase counterfeiting, and given that the costs of manufacturing cigarettes for the illicit market on a large scale are so low the presence of branding on packaging is unlikely to impact upon these costs in any meaningful way. ${ }^{4}$ And the predicted price war, should it materialise, would actually reduce the 
appeal of illicit sources. Second, the suggestion that plain packaging would stimulate more price competition is not an argument against its introduction, but for pricing regulation.

Legality: Tobacco companies argue that plain packaging would breach intellectual property rights and contravene international trade agreements. They accept that there are exemptions to these principles on the grounds of public health, but then argue that the evidence on the public health gain from plain packaging is weak and hence the measure is not proportionate $\cdot \frac{3,5-7}{3}$ However, this position is undermined by industry documents which show that they consider the protections of both intellectual property and trade agreements to be insufficient to prevent plain packaging from being introduced. ${ }^{8,9}$ This would suggest that they are unlikely to have a successful legal challenge to the move towards plain packaging in Australia..$^{10,11}$

Proportionality: Nonetheless, the issue of proportionality remains, and regulators must show a clear public health gain to justify introducing plain packaging. At the third Conference of Parties for the Framework Convention on Tobacco Control ${ }^{12, \underline{13}}$ plain packaging was recognised to have three such benefits: it would 1) reduce the promotional appeal of the pack, $\frac{14}{2}$ ) make the health warnings more prominent and effective, $\stackrel{15,16}{ }$ and 3) prevent the use of design elements, such as colours, which consumers often erroneously see as indicators of product safety. ${ }^{17}$ A review of existing plain packaging research found that all studies located had explored, and found support for, at least one of these three benefits. $\underline{18}$ 
The tobacco industry, however, question the strength of this evidence base, and in particular argue that studies to date have been artificial measures of the perceived effects of plain packaging, rather than real world measures of actual effects..$^{3,5-7}$ Real world effects are, of course, difficult to assess until the measure is actually introduced, so there is a danger of this objection becoming a barrier to progress.

We attempted to get around this impasse by conducting a real world test of plain packaging. A group of smokers were given plain packs and asked to use them, instead of their normal branded ones, for two weeks. For two weeks, they transferred their cigarettes to plain packs provided, but otherwise smoked and socialised as normal. For the other two weeks the smokers used their own packs. This is the first attempt at a 'naturalistic' type study of plain packaging.

\section{METHODS}

\section{Sample selection}

The study involved four separate, but related stages, conducted with young adult smokers aged 18-35 years old, recruited in Greater Glasgow by market recruiters. Young adult smokers were recruited for two reasons; 1) Industry documents reveal 18-35 year olds to be key target groups,,$\underline{19, \underline{20}}$ and 2) Smoking prevalence is particularly high among this age group in the UK..$^{21,22}$

\section{Design and Procedure}

The first stage of the research involved eight focus groups with 54 smokers, in February 2010, to explore perceptions of cigarette packaging and plain packaging, but also to inform and guide the naturalistic study by exploring: an appropriate plain pack 
colour to use (dark grey, light grey, dark brown or light brown/biege); a suitable neutral fictitious brand name for the plain packs (either Kerrods, Standards or Netral); and perceived difficulties with using plain packs in real-life settings. Dark brown was perceived as the least appealing colour in all groups, and the fictitious brand name Kerrods elicited neither positive nor negative associations. As such, dark brown plain packs with the brand name Kerrods were used in the naturalistic study. A suggestion to increase compliance was to provide smokers with the cigarettes already contained within the plain packs. Although a viable option we decided against this as smokers who otherwise may quit would be encouraged to continue and also because of the additional costs required for supplying pre-packaged cigarettes.

A pre-pilot naturalistic study was then conducted with six smokers, in March 2010, who were provided with 14 plain packs (without cigarettes inside) and asked to transfer cigarettes from their packs into the plain packs each day for a two-week period. They were also asked to complete identical questionnaires every second day for these two weeks. Questionnaires were developed by the research team, primarily from smokers' reactions to plain packs within the focus groups, and covered five areas; Pack perceptions, Pack feelings, Feelings about smoking, Health warnings (measured on five-point scales), and Behavioural change/avoidant behaviour (measured via yes/no responses). The items on behaviour change and avoidant behaviour were adapted from the International Tobacco Control project. Two focus groups were subsequently employed to explore participants' experience of using the plain packs, completing and comprehension of the questionnaires, and any aspects of the study protocol that could be improved. Smokers did not question the authenticity of the Kerrods packs or highlight any problems transferring their cigarettes into these packs, which took only a minute or so. All reported using the packs for the two 
weeks, although one smoker reported not using the pack on a night out after he ran out. The two groups thought that the questionnaire was comprehensible but completing it every second day was cumbersome.

The main naturalistic study ran from May to June 2010. Young adult smokers $(\mathrm{N}=140)$ were recruited from 14 randomly selected postcode sectors in Greater Glasgow, using random location quota sampling. The Fourteen Postcode Sectors were randomly selected, stratified by DEPCAT score (a measure of multiple deprivation), to ensure coverage of a range of socio-economic backgrounds. Within each selected Postcode Sector ten participants were recruited, using the door knock method, according to quota controls on age, gender and social grade. All potential participants were informed that the study was concerned with smokers' experiences of, and opinions about, tobacco packaging. If individuals indicated that they were willing to participate, and available for the study duration, they were asked to complete a recruitment questionnaire which included questions on consumption and cessation behaviour (motivation to quit, attempts to quit). If they satisfied the criteria for study inclusion participants were instructed on what they were required to do throughout the study period and given a 'completion' pack; this contained the 14 plain packs, the questionnaires (labelled by day and date) and a timetable explaining when to use the plain packs and when to use their own packs, and also when to complete each of the questionnaires.

The study ran for four weeks. For either the first or last two weeks, participants were instructed to transfer cigarettes from their own pack into the packs supplied to them and then use these packs; ordering was randomised with half using the plain pack in the first two weeks and half in the last two weeks. The same text message was used on the pack front (Smoking Kills) and the same pictorial image of 
diseased and healthy lungs on the rear panel to minimise costs - in the UK all cigarette packs carry one of two text warnings on the front panel of the pack and one of fourteen pictorial warnings on the rear panel. Participants were also instructed to complete questionnaires twice a week and return them via pre-addressed envelopes or email. This resulted in four questionnaires relating to their experience of the plain packs and four for their own packs. The questionnaires were identical to those used in the pre-pilot study but were only to be completed twice a week, rather than every second day, to reduce the burden on participants. In an attempt to manage sample maintenance, market recruiters were instructed to text respondents once a week reminding them to complete and return the questionnaires and to use the correct pack (their own pack or the plain pack), as specified by the timetable. A member of the research team also sent an email, once a week, to participants who had provided an email address, as an additional reminder to complete and return the questionnaires. Participants received $£ 20$ for using the packs and $£ 2.50$ per questionnaire returned.

From the 140 smokers recruited in the main study 50 were phoned and invited to participate in a follow-up interview in the week following study completion; 20 could not be reached by telephone (after five attempts), seven declined to take part, and five reported not participating in the study and were deemed ineligible. Reasons for non-participation was personal or familial health problems for three respondents, giving up smoking for one respondent and losing the packs for another. Those who could not be contacted did not differ from those who completed, or refused to complete, the interview, in terms of age, gender, social grade or smoking behaviour. Participants comprised nine males and nine females, 12 aged 25-35 and six aged 1824, and seven from social grade $\mathrm{ABC} 1$ and 11 from social grade $\mathrm{C} 2 \mathrm{DE}$. A semistructured topic guide was developed to explore the same themes covered in the 
questionnaire. Interviews lasted approximately thirty minutes. Each interviewee received $£ 10$ for participation.

\section{Analysis}

At the analysis stage, some items were recoded to ensure the same direction of coding and thus facilitate interpretation and creation of composite variables. Composite scores were derived for pack perceptions, pack feelings, feelings about smoking and response to warnings by summing the individual items within each and then rescaling to a five-point scale. Cronbach's alpha was acceptable for each, thus supporting the decision to create composite scores at each wave and for each pack type; although Cronbach's scores for pack perceptions of Kerrods at the first and third measure (0.66 and 0.69 respectively), and overall pack feelings of own pack at the second measure (0.63), were marginally lower.

Analysis focused on comparing ratings between branded and plain packs. To ensure packs were compared against equivalent time points ratings of the plain pack at the first, second, third and fourth measures were compared with ratings of participant's own pack at the first, second, third and fourth measures, respectively. For each time point, paired t-tests were used to produce mean scores for the plain packs relative to mean scores for their own pack. Given the ordinal nature of the fivepoint scales, the Wilcoxon Signed Rank test, a non-parametric procedure suited to paired data, was used to test for significant differences between ratings of plain packs versus participant's own packs at each measure. Data on occurrence of avoidant behaviours is binary (yes/no) and the McNemar test was used to test for differences in response between participants first, second, third and fourth measure on the plain pack and the respective measure on their own pack. 


\section{RESULTS}

\section{Naturalistic study}

From the 140 participants recruited, 34 (25\%) were non-completers, who failed to participate at all, $58(41 \%)$ were partial completers (who participated but did not return all the questionnaires or report using the correct pack), and 48 (34\%) were completers, who completed the full study as intended. Non-completers, with a mean age of $23(\mathrm{SD}=4.7)$, were younger than both completers $(\mathrm{M}=27, \mathrm{SD}=5.5)$ and partial completers $(\mathrm{M}=28, \mathrm{SD}=5.5)$. There was no marked difference in participation, however, by amount smoked, motivation to quit or attempts to quit. Analysis focuses only on the 48 completers.

\section{Pack Perceptions}

On average, participants rated Kerrods negatively on all pack perceptions (not stylish, unfashionable, cheap, uncool, unattractive, poor quality, unappealing), with mean scores ranging from 1.35 to 2.07 ; lower scores indicating more negative perceptions (see Table 1a). For their own packs, mean scores ranged from 2.64 to 3.48 , indicating more positive perceptions. For the overall pack perception score, participants rated the Kerrods pack more negatively than their own pack. Overall ratings did not vary across time for either pack.

Table 1 here

\section{Pack Feelings}


On average, participants reported more negative feelings (embarrassed, ashamed, unaccepted) about using the Kerrods pack, relative to their own pack (see Table 1b). For the Kerrods pack, mean scores ranged from 2.24 to 2.70, whereas mean scores for their own pack ranged from 3.18 to 4.20 . Overall ratings did not vary across time for either pack.

\section{Feelings about smoking}

Participants reported more negative feelings about smoking from the Kerrods pack (see Table 1c). Participants, on average, rated the smoking experience with their own packs as more 'enjoyable' (mean scores 3.13 to 3.37) and 'satisfying' (mean scores 3.13 to 3.35 ) than for the Kerrods packs, rated as less 'enjoyable' (mean scores 2.53 to 2.78) and 'satisfying' (mean scores 2.58 to 2.70). Overall ratings for Kerrods did not vary across time. However, the average overall feelings about smoking from their usual pack were less positive at the third and fourth measures compared with the first.

\section{Health warnings}

For both packs, participants rated the warnings as being noticeable (mean scores 3.39 to 4.11 ), serious (3.85 to 4.28 ), believable (4.09 to 4.34 ) and highlighting the health risks of smoking (3.67 to 3.98), see Table 1d. At the first and second measures only, warnings on the Kerrods pack were rated as more noticeable relative to their own pack. At the fourth measure only, warnings on Kerrods packs were rated as more serious. However, overall ratings of the warnings did not differ between the packs, and did not vary across time for either pack.

\section{Behavioural change/avoidant behaviour}


Across all four measures, participants indicated greater occurrence of the following actions when using the Kerrods packs: keeping the pack out of sight; covering the pack; smoking less around others; thinking about quitting. In addition, when using the Kerrods pack, participants were always more likely to forgo a cigarette (although only significantly so at the third and fourth measures), and always more likely to indicate that they wanted to quit (although only significantly so at the second and fourth measures).

Table 2 here

Post-study interviews

\section{Pack Perceptions}

About half $(\mathrm{N}=10)$ of the 18 smokers who participated in the interviews perceived the Kerrods pack as less appealing, see Table 3. Despite these negative perceptions, the durability of the Kerrods pack was viewed as similar to branded packs.

\section{Pack Feelings}

Five (female) smokers said they felt embarrassed or guilty when using the Kerrods pack, often because of the attention it drew from others (see Table 3). Some liked this attention but, as was found in the pre-pilot focus groups (not previously reported), they acknowledged that it was due to a novelty factor which would not exist if all cigarette packs on the market were brown.

\section{Feelings about smoking}


Twelve smokers reported not feeling any differently when using the Kerrods pack.

Six (five females) said that even though they knew it was their own brand inside the Kerrods pack, it felt like they were smoking cheap cigarettes or that the cigarettes did not taste as good (see Table 3).

Table 3 here

\section{Health warnings}

Twelve smokers thought the warnings on Kerrods packs were just as salient, believable and serious as on branded packs. Six considered the warnings on the Kerrods packs more salient, five more believable and four more serious (see Table 4).

\section{Behavioural change/avoidant behaviour}

About half $(\mathrm{N}=8)$ reported some change in their smoking behaviour when using the Kerrods pack; again mostly females $(\mathrm{N}=6)$. This included taking out cigarettes less often, handing out cigarettes less frequently and hiding the pack more. Three females also reported reducing their usual consumption levels. Reasons given for avoidant behaviour, or behaviour change, included the pack colour, the reactions from others, and the more prominent warnings (see Table 4). Three smokers suggested that if all cigarettes came in the dark brown packs they would consider quitting.

I would definitely try to quit (Female, 25-35, C2DE) 
Of the ten smokers who perceived no change in their smoking behaviour, when asked about the possible impact of plain packaging on youth, six thought it would deter them from starting.

A person might think that maybe smoking is a disgusting habit. It's brown, the colour of crap and the crap I'm putting in my lungs and smoking, over time, might just get less and less appealing to them (Male, 18-24, C2DE)

For the four smokers who thought that plain packaging did not, and would not, have any effect on them, or others, they explained that smoking is an addiction and it is the cigarette, not the pack, which is important.

At the end of the day it is not the packet you are smoking, it is the cigarettes in the packet. It is the cigarette you are addicted to and not the cardboard box (Male, 25-35, C2DE)

Table 4 here

\section{DISCUSSION}

Employing an innovative methodology we explored young adult smokers' perceptions of using non-branded packaging on a daily basis. The study used, for the first time, a naturalistic design, but our findings are consistent with past research. First, warnings on dark brown 'plain' packs were rated as more salient than on branded packs, at least at the first and second measures, and for a third of those in the post-study interview. 
Other smokers pointed out that the increased salience increased thoughts about the harms of tobacco.

Second, plain packs had less promotional appeal, being perceived negatively throughout the study. The pack colour, distinct from all other brands on the UK market, was viewed as unattractive by smokers and others. The use of a faecal brown pack colour appeared to both destroy the symbolism of tobacco branding and heighten the awareness of associated health risks. For instance, one smoker commented that 'Even the colour of the pack just made me think, oh God, are my lungs this colour as well?' These negative perceptions often resulted in embarrassment, shame or guilt. Although we did not explore gender differences in the quantitative analyses, the poststudy interviews strongly suggests that these negative pack perceptions and feelings are most pronounced for females, and considerably less so for lower income males. Interestingly, some smokers reported positive feelings when first using the plain packs but in both the pre-pilot focus groups and post-study interviews all smokers who reported a positive 'novelty effect' described it as transient and claimed that it would not exist if the dark brown packs were the norm, i.e. if plain packaging was mandated.

Third, we found that plain packaging was associated with changes in the sensory perceptions of the product, known as 'sensory transfer', where pack colour affected taste perceptions. ${ }^{23,24}$ Approximately a third of smokers in the post-study interviews reported that their cigarettes did not taste as good from the brown pack even though it was their normal brand of cigarettes. The removal of familiar, and often reassuring, branding not only altered perceptions of product taste, but for some it was associated with, or appeared to directly trigger, avoidant behaviour (e.g. covering the pack), a reduction in consumption and increased thoughts of quitting. This was apparent in both the quantitative analyses and post-study interviews. This 
effect on avoidant and smoking cessation behaviours requires verification, but it is a direct benefit of the naturalistic design employed, which makes it possible to uncover real world effects.

The study has its limitations, most notably the small sample size - exacerbated by high attrition and some failure to correctly comply with study protocol. This was however a pilot study, with a high level of participant involvement, intended to explore the feasibility of such research and allow some insights into smokers' perceptions of plain packaging in real-world settings. Future research could deploy greater resources and recruit a larger and nationally representative sample. The study protocol could also be simplified, particularly by providing smokers with their own brand of cigarettes already in plain packs. This would help reduce attrition and eliminate the need for smokers to transfer the cigarettes into plain packs, especially as it is impractical to verify that all smokers did so. This option was suggested in the focus groups but our limited pilot-study resources precluded adopting the idea. Another possibility to increase compliance is to provide larger incentives for participation and reduce the length of the study period.

The use of a generic brand name, even though neutral, may have affected participant's perceptions of plain packaging. Although providing each smoker with plain packs carrying the name of their brand was not possible in this study for legal reasons, given a possible breach of copyright, future research should consider the role and importance that brand name may have for smokers in the event of plain packaging. Another limitation is that the study is dependent on self-reports, in terms of reported behaviour change and the use of Kerrods packs. For the latter, reported use may also have been inflated by socially desirable responding. Aside from providing cigarettes within packs, it is difficult, however, to envisage an alternative 
approach when using naturalistic research. The study also provides no insight into the potential impact that plain packaging may have for older adult smokers.

\section{CONCLUSION}

Notwithstanding the small sample size, this is the first naturalistic study of plain packaging and it adds an important real world dimension to the evidence base. As well as confirming the general lack of appeal of plain packs, some adult smokers reported decreased enjoyment and consumption as a direct result of using plain packs, and others claimed that they would attempt to quit if all cigarettes came in dark brown unbranded packs. This suggests that plain packaging has an important potential role to play in helping smokers, and based upon the post-study interviews particularly female smokers, on the road to becoming smoke free.

\section{What this paper adds}

- Past research on plain (unbranded) tobacco packaging suggests that the removal of branding from packaging may help to increase the salience and seriousness of health warnings, reduce the appeal of both the package and of smoking, and promote cessation behaviour.

- A 'naturalistic' design was employed where young adult smokers were asked to smoke their own brand of cigarettes, as normal, for a period of four weeks, but for two of these four weeks they were to transfer their cigarettes to dark brown 'plain' packs that had been provided to them and use these packs. For the other two weeks they were to use their regular branded packs as normal. The study is the first to attempt to provide a real world measure of the possible impact plain packaging. The findings show that in comparison with branded 
packaging, the use of plain packs resulted in more negative perceptions and feelings about the pack, more negative feelings about smoking, and for some smokers it also increased avoidant behaviours such as covering the pack, and cessation behaviours such as forgoing cigarettes and thinking about quitting.

\section{Acknowledgements}

We would like to thank an advisory group (Deborah Arnott, Karine Gallopel-Morvan,

David Hammond, Heather Wardle) for providing advice on the study design and methodology, and to Diane Dixon for helping co-ordinate the study. 


\section{References}

1. Lee B. Sell tobacco in no-frills wrappers, urge doctors. News and comments, The Journal, 1 October, 1986. http://legacy.library.ucsf.edu/tid/jxd28a99

2. Euromonitor International. Tobacco in Russia, 2008.

http://www.euromonitor.com/Tobacco_in_Russia (accessed 15 June 2010)

3. Philip Morris Limited. Philip Morris Limited's response to the Department of Health's consultation on the future of tobacco control, 8 September 2008.

http://www.plain-

packaging.com/downloads/PM_Submission_to_UK_DOH_consultation_Sep_08.pdf (accessed 15 March 2011)

4. Moodie C, Hastings GB, Joossens L. Young adult smokers' perceptions of illicit tobacco and the possible impact of plain packaging on illicit tobacco purchasing behaviour. Eur J Pub Health (forthcoming).

5. British American Tobacco. British American Tobacco response to the Department of Health discussion document "Consultation on the future of tobacco control, May 2008”, September 2008.

http://www.bat.com/group/sites/uk 3mnfen.nsf/\%20vwPagesWebLive/DO7J7CSX/ \$FILE/medMD7J7CUJ.pdf?openelement (accessed 15 March 2011)

6. Imperial Tobacco. Imperial Tobacco Group PLC Response to UK Government proposals to ban the display of tobacco products, December 9, 2008. 
http://www.imperial-tobacco.com/index.asp?page=78\&newsid=647 $($ accessed 25

February 2009)

7. Japan Tobacco International. Response to the UK Department of Health's consultation on the future of tobacco control. 5 September 2008.

http://www.jti.com/file.axd?pointerID=aa297df9609d4625aefbd91777528d05. (accessed 25 February 2009)

8. Freeman B, Chapman S, Rimmer M. The case for the plain packaging of tobacco products. Addiction 2008;103:580-90.

9. Physicians for Smoke-Free Canada. Packaging phoney intellectual property claims. Ottawa, Ontario: Physicians for Smoke-Free Canada, 2009.

10. McGrady B. TRIPs and trademarks: the case of tobacco. World Trade Review $2004 ; 3,53-82$.

11. Davison M. Big Tobacco's huff and puff is just hot air. The Age Newspaper, Australia, 4 May 2010. http://www.smh.com.au/opinion/society-and-culture/bigtobaccos-huff-and-puff-is-just-hot-air-20100503-u3p0.html (accessed 8 September 2010)

12. World Health Organization (2008). Elaboration of guidelines for implementation of Article 11 of the Convention. Third session of the Conference of the Parties to the 
WHO Framework Convention on Tobacco Control. Durban, South Africa, 17-22 November 2008.

http://www.who.int/fctc/guidelines/article_11.pdf

13. World Health Organization (2008). Elaboration of guidelines for implementation of Article 13 of the Convention. Third session of the Conference of the Parties to the WHO Framework Convention on Tobacco Control. Durban, South Africa, 17-22 November 2008. http://apps.who.int/gb/fctc/PDF/cop3/FCTC COP3 9-en.pdf

14. Centre for Health Promotion. Effects of plain packaging on the image of tobacco products among youth. University of Toronto: Centre for Health Promotion, 1993.

15. Beede $\mathrm{P}$, Lawson $\mathrm{R}$. The effect of plain packages on the perception of cigarette health warnings. Pub Health 1992;106:315-22.

16. Hoek J, Wong C, Gendall P, Louviere J, Cong K. Effects of dissuasive packaging on young adult smokers. Tob Control (forthcoming).

17. Hammond D, Dockrell M, Arnott D, Lee A, McNeill A. Cigarette pack design and perceptions of risk among UK adults and youth. Eur J Pub Health 2009:19:631-7.

18. Moodie C, Hastings G, Ford A. A brief review of plain packaging research for tobacco products. Report prepared for the Department of Health, 2009. http://www.ctcr.stir.ac.uk/pdf docs/Review\%20of\%20Plain\%20Packaging.pdf 
19. M\&C Saatchi. Sovereign and the cheap cigarette market qualitative research debrief (version 1 of 2), 1998. http://www.tobaccopapers.com/PDFs/05000599/0564.pdf

20. Leading Edge. American blends NPD. Qualitative debrief presentation, 1997. http://www.tobaccopapers.com/PDFs/0400-0499/0479.pdf

21. British Medical Association. Breaking the cycle of children's exposure to tobacco smoke. London: British Medical Association, 2007.

22. NHS Information Centre. Statistics on smoking: England, 2009. London: The Information Centre, NHS, 2009.

23. Wakefield M, Germain D, Durkin SJ. How does increasingly plainer cigarette packaging influence adult smokers' perceptions about brand image? An experimental study. Tob Control 2008;17:416-21.

24. Germain D, Wakefield M, Durkin S. Adolescents' perceptions of cigarette brand image: does plain packaging make a difference? J Adolesc Health 2010;46:385-92. 
Table 1. Mean ratings on response to Kerrods pack v Own pack

\begin{tabular}{|c|c|c|c|c|c|c|c|c|}
\hline & \multicolumn{2}{|c|}{ 1st Measure } & \multicolumn{2}{|c|}{ 2nd Measure } & \multicolumn{2}{|c|}{ 3rd Measure } & \multicolumn{2}{|c|}{ 4th Measure } \\
\hline & $\begin{array}{c}\text { Kerrods } \\
\text { mean } \\
s d\end{array}$ & $\begin{array}{l}\text { Own } \\
\text { mean } \\
s d \\
\end{array}$ & $\begin{array}{c}\text { Kerrods } \\
\text { mean } \\
s d\end{array}$ & $\begin{array}{c}\text { Own } \\
\text { mean } \\
s d \\
\end{array}$ & $\begin{array}{c}\text { Kerrods } \\
\text { mean } \\
s d \\
\end{array}$ & $\begin{array}{c}\text { Own } \\
\text { mean } \\
s d \\
\end{array}$ & $\begin{array}{c}\text { Kerrods } \\
\text { mean } \\
s d \\
\end{array}$ & $\begin{array}{c}\text { Own } \\
\text { mean } \\
s d \\
\end{array}$ \\
\hline \multicolumn{9}{|l|}{ a) Pack Perceptions (7 items) } \\
\hline Style & 1.43 & $3.09^{* * *}$ & 1.36 & $3.07^{* * * *}$ & 1.35 & $2.87^{* * *}$ & 1.42 & $2.91 * * *$ \\
\hline not stylish(1)/stylish(5) & 0.59 & 0.88 & 0.61 & 0.79 & 0.57 & 0.91 & 0.66 & 0.97 \\
\hline Fashion & 2.05 & $3.00^{* * *}$ & 1.84 & $2.77^{* *}$ & 1.89 & $2.80^{* *}$ & 2.04 & $2.80 * * *$ \\
\hline unfashionable(1)/fashionable(5) & 1.51 & 0.91 & 1.38 & 0.74 & 1.32 & 0.84 & 1.38 & 0.84 \\
\hline Cheap & 1.62 & $3.20^{* * * *}$ & 1.66 & $3.00^{* * * *}$ & 1.57 & $3.13^{* * *}$ & 1.65 & $3.15 * * *$ \\
\hline cheap(1)/expensive(5) & 0.75 & 1.01 & 0.81 & 1.01 & 0.69 & 0.98 & 0.74 & 1.07 \\
\hline Cool & 1.57 & $2.64^{* * * *}$ & 1.64 & $2.84^{* * *}$ & 1.42 & $2.84^{* * *}$ & 1.57 & $2.87 * * *$ \\
\hline uncool(1)/cool(5) & 0.76 & 0.84 & 0.88 & 0.74 & 0.62 & 0.80 & 0.75 & 0.86 \\
\hline Attractive & 1.59 & $3.05^{* * *}$ & 1.43 & $2.87^{* * * *}$ & 1.54 & $2.87^{* * *}$ & 1.67 & $2.84 * * *$ \\
\hline unattractive(1)/attractive(5) & 0.97 & 0.96 & 0.86 & 0.83 & 0.86 & 0.93 & 0.90 & 0.82 \\
\hline Quality & 2.05 & $3.43^{* * *}$ & 2.07 & $3.48^{* * * *}$ & 1.91 & $3.40^{* * * *}$ & 1.89 & $3.40 * * *$ \\
\hline poor quality(1)/good quality(5) & 0.96 & 0.83 & 0.93 & 0.73 & 0.85 & 0.86 & 0.88 & 0.78 \\
\hline Appealing & 1.76 & $3.07^{* * *}$ & 1.84 & $3.07^{* * * *}$ & 1.76 & $3.02^{* * *}$ & 1.71 & $2.93 * * *$ \\
\hline unappealing(1)/appealing(5) & 1.08 & 1.07 & 1.16 & 0.90 & 0.98 & 0.87 & 0.89 & 0.94 \\
\hline \multicolumn{9}{|l|}{ Overall Pack Perceptions } \\
\hline Composite score & 1.72 & $3.05^{* * *}$ & 1.70 & $3.03^{* * * *}$ & 1.63 & $3.00^{* * *}$ & 1.73 & $3.01 * * *$ \\
\hline $\begin{array}{l}\text { Low score }=\text { negative perceptions } / \text { High score }=\text { positive } \\
\text { perceptions }\end{array}$ & 0.57 & 0.59 & 0.62 & 0.56 & 0.51 & 0.63 & 0.57 & 0.65 \\
\hline \multicolumn{9}{|l|}{ b) Pack Feelings (3 items) } \\
\hline Embarrassment & 2.30 & $4.20^{* * *}$ & 2.33 & $3.96^{* * * *}$ & 2.30 & $3.83^{* * * *}$ & 2.26 & $3.70 * * *$ \\
\hline embarrassed(1)/not (5) & 1.17 & 0.96 & 1.33 & 1.01 & 1.16 & 1.09 & 1.18 & 1.15 \\
\hline Ashamed & 2.70 & $4.11^{* * * *}$ & 2.39 & $3.89^{* * * *}$ & 2.47 & $3.71^{* * *}$ & 2.39 & $3.80 * * *$ \\
\hline $\operatorname{ashamed}(1) / \operatorname{not}(5)$ & 1.21 & 1.02 & 1.28 & 1.02 & 1.16 & 1.18 & 1.18 & 1.05 \\
\hline Acceptance & 2.30 & $3.52^{* * *}$ & 2.37 & $3.30^{* * * *}$ & 2.44 & $3.18^{* * * *}$ & 2.24 & $3.24 * * *$ \\
\hline unaccepted(1)/accepted(5) & 0.90 & 0.90 & 1.07 & 0.86 & 1.06 & 0.91 & 0.98 & 1.03 \\
\hline \multicolumn{9}{|l|}{ Overall Pack Feelings } \\
\hline Composite score & 2.45 & $3.96^{* * *}$ & 2.40 & $3.76^{* * * *}$ & 2.42 & $3.56^{* * *}$ & 2.32 & $3.61 * * *$ \\
\hline
\end{tabular}


Low score $=$ negative perceptions $/$ High score $=$ positive

\begin{tabular}{|c|c|c|c|c|c|c|c|c|}
\hline perceptions & 0.95 & 0.71 & 1.04 & 0.72 & 1.03 & 0.94 & 1.00 & 0.89 \\
\hline \multicolumn{9}{|l|}{ c) Feelings about smoking ( 2 items) } \\
\hline Enjoyment & 2.53 & $3.37^{* * * *}$ & 2.73 & $3.30^{* *}$ & 2.78 & $3.13^{*}$ & 2.62 & $3.18 * * *$ \\
\hline not at all enjoyable(1)/very enjoyable(5) & 0.88 & 0.85 & 1.06 & 0.79 & 1.06 & 0.84 & 0.96 & 0.98 \\
\hline Satisfaction & 2.65 & $3.35^{* * *}$ & 2.58 & $3.22^{* * * *}$ & 2.70 & $3.13^{* *}$ & 2.61 & $3.20 * * *$ \\
\hline not at all satisfying(1)/satisfying(5) & 1.00 & 0.87 & 1.10 & 0.79 & 1.02 & 0.82 & 1.02 & 0.96 \\
\hline \multicolumn{9}{|l|}{ Overall Feelings Smoking } \\
\hline Composite score & 2.60 & $3.36^{* * * *}$ & 2.67 & $3.28^{* *}$ & 2.77 & $3.11^{*}$ & 2.63 & $3.17 * * *$ \\
\hline \multicolumn{9}{|l|}{ d) Health Warnings (4 items) } \\
\hline Noticing & 4.11 & $3.39^{*}$ & 4.05 & $3.61^{*}$ & 4.07 & 3.64 & 4.05 & 3.77 \\
\hline hardly noticeable(1)/very(5) & 0.95 & 1.33 & 0.99 & 1.08 & 0.91 & 1.15 & 1.06 & 1.14 \\
\hline Seriousness & 4.11 & 3.93 & 4.22 & 3.89 & 4.13 & 3.85 & 4.28 & $3.87 * * *$ \\
\hline not serious(1)/very serious(5) & 0.98 & 1.03 & 0.84 & 1.04 & 1.01 & 1.00 & 0.89 & 1.00 \\
\hline Believability & 4.30 & 4.12 & 4.24 & 4.10 & 4.28 & 4.09 & 4.34 & 4.18 \\
\hline not believable(1)/believable(5) & 0.83 & 0.93 & 0.91 & 1.03 & 0.91 & 0.98 & 0.86 & 0.97 \\
\hline not at all aware(1)/very aware(5) & 1.25 & 1.09 & 1.15 & 1.06 & 1.17 & 1.15 & 0.95 & 1.18 \\
\hline \multicolumn{9}{|l|}{ Overall Warning Response } \\
\hline Composite score & 4.07 & 3.78 & 4.10 & 3.82 & 4.07 & 3.83 & 4.15 & 3.94 \\
\hline Low score $=$ little/no impact $/$ High score $=$ high impact & 0.80 & 0.80 & 0.78 & 0.82 & 0.79 & 0.91 & 0.77 & 0.87 \\
\hline
\end{tabular}


Table 2. Proportion of participants reporting behaviour change or avoidant behaviour as a result of pack

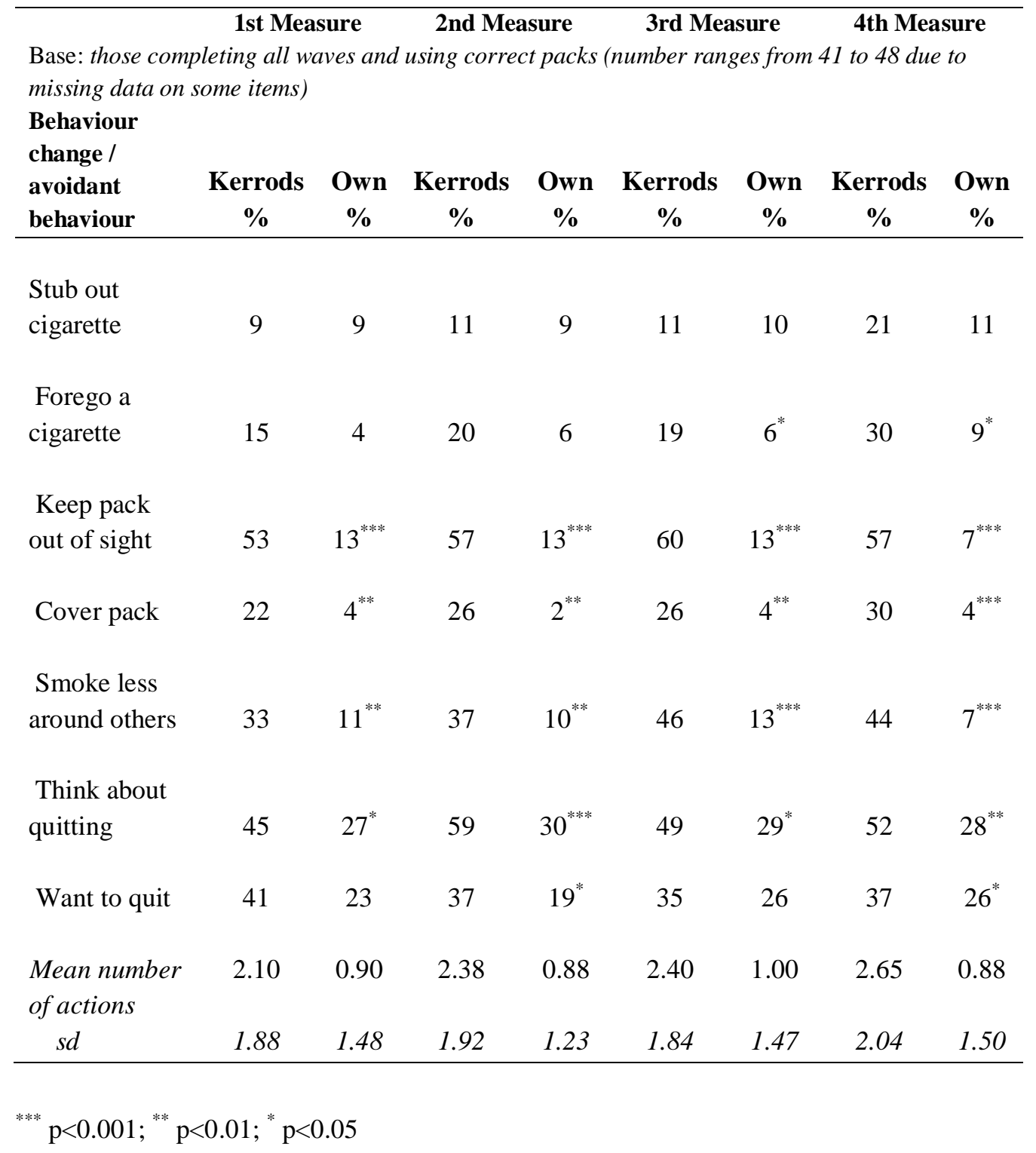


Table 3. Smokers' perceptions and feelings of packaging and smoking in the poststudy interview

\begin{tabular}{|c|c|}
\hline & Examples of respondent comments \\
\hline \multirow[t]{4}{*}{$\begin{array}{l}\text { Pack } \\
\text { perceptions }\end{array}$} & $\begin{array}{l}\text { The brown packet, yeh, like I say it isn't really a nice colour...I think } \\
\text { it's because like, tobacco is brown, so therefore you're thinking of } \\
\text { tobacco rather than cigarettes (Male, 25-35, ABC1) }\end{array}$ \\
\hline & $\begin{array}{l}\text { Not a fan, I wouldn't buy them. But then that is a good thing then } \\
\text { really isn't it? (Female, 25-35, ABC1) }\end{array}$ \\
\hline & $\begin{array}{l}\text { Even the colour of the pack just made me think, oh God, are my } \\
\text { lungs this colour as well? (Female, 25-35, C2DE) }\end{array}$ \\
\hline & $\begin{array}{l}\text { It's a kind of, I don't know what's the best word for it, a kind of a } \\
\text { pooey colour (Male, 25-35, ABC1) }\end{array}$ \\
\hline \multirow[t]{4}{*}{$\begin{array}{l}\text { Pack } \\
\text { feelings }\end{array}$} & $\begin{array}{l}\text { With the brown pack I did feel a wee bit, not ashamed, but I did feel } \\
\text { different (Female, 18-24, ABC1) }\end{array}$ \\
\hline & $\begin{array}{l}\text { Embarrassed to take them out and show people (Female, 25-35, } \\
\text { C2DE) }\end{array}$ \\
\hline & $\begin{array}{l}\text { It made me feel bad and gave me a guilty conscience (Female, 25- } \\
35, \mathrm{C} 2 \mathrm{DE})\end{array}$ \\
\hline & $\begin{array}{l}\text { On a Saturday night I was more conscious of taking the packet out, } \\
\text { not so much during the week, it didn't really bother me during the } \\
\text { week...it was more when I as out in the pub on a Saturday when I } \\
\text { was quite mortified (Female, } 18-24, \mathrm{ABC} 1 \text { ) }\end{array}$ \\
\hline \multirow[t]{4}{*}{$\begin{array}{l}\text { Feelings } \\
\text { about } \\
\text { smoking }\end{array}$} & $\begin{array}{l}\text { Smoking never really bothered me, like it was just something that I } \\
\text { done and it never really bothered me, until I was using the brown } \\
\text { pack because obviously the colour and how noticeable it was when } \\
\text { you pulled them out the packet. It definitely did feel more horrible to } \\
\text { actually smoke (Female, 18-24, ABC1) }\end{array}$ \\
\hline & $\begin{array}{l}\text { It made me feel horrible aye. Even though it's still my cigarettes and } \\
\text { they were my own make in the pack, I did still feel, mm, should I be } \\
\text { doing this or not? (Female, 18-24, C2DE) }\end{array}$ \\
\hline & Ifelt like I was smoking a cheap cigarette (Male, 25-35, C2DE) \\
\hline & It almost didn't taste as good (Female, 25-35, C2DE) \\
\hline
\end{tabular}


Table 4. Smokers' perceptions of health warnings on plain packs and avoidant behaviour and behavioural change

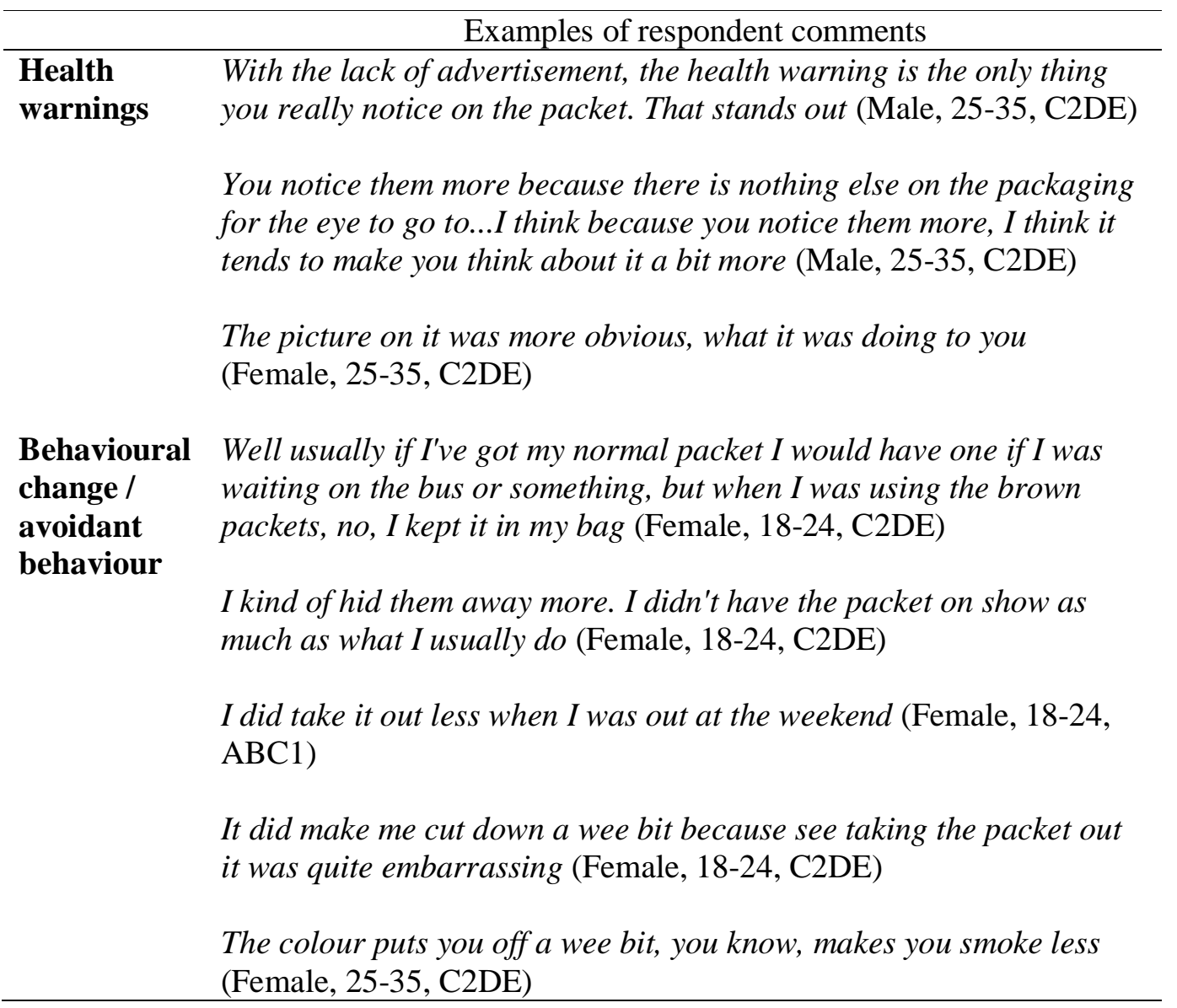

